\title{
CAROTID OR CORONARY INTERVENTION WHICH IS TO BE DONE FIRST ?
}

\author{
Ravikiran. M, Afshan Jabeen , Nemani Lalita
}

\begin{abstract}
:
In carotid artery disease patients with concomitant significant coronary artery disease (CAD - especially left main diseases - LMCA), the risk of perioperative myocardial infarction and early and late death are increased. Conversely, in patients undergoing coronary artery bypass surgery $(C A B G)$, uncorrected severe carotid disease increases the risk of adverse neurologic events [1]. The optimal management of these co-existing conditions and the timing and sequence of correcting them remain controversial. Over the past 2 decades, staged carotid revascularisation followed by CABG, staged CABG followed by carotid revascularisation, or combined coronary and carotid revascularisation simultaneously in one operative setting have each been advocated. Our patient presented with both carotid and significant LMCA CAD, first we have done carotid intervention followed one week later by LMCA percutaneous coronary intervention (PCI).
\end{abstract}

Key words: Carotid angioplasty, Coronary angioplasty, CABG.

\section{CASE DETAILS:}

A 71 year old male came with complaints of pre-syncope since 5 days, transient weakness of left upper limb and lower limb, transient parasthesias in left upper limb and lower limb. He has no history of fall or loss of consciousness, seizures, chest pain, shortness of breath , palpitation. He has history of hypertension and diabetes mellitus. He has history of esophageal carcinoma for which he underwent chemotherapy and radiotherapy 1 year back. He has history of PCI to RCA and PDA two years back. At admission his pulse rate was $80 /$ minute and blood pressure was 120/80 $\mathrm{mm}$ of $\mathrm{Hg}$. General and systemic examination were normal, he has no neurological deficit. Neurologist consultation was taken and a provisional diagnosis of transient ischemic attacks (TIAs) in right MCA territory was made and necessary investigations were done. Hemoglobin was $11.3 \mathrm{gm} / \mathrm{dl}$, TLC was 9100 cells $/ \mathrm{mm} 3$, platelet count was 2.5

Article received on 01 OCT 2016, published on 31 OCT 2016.

Ravi Kiran .M ${ }^{1}$, S. Afshan Jabeen ${ }^{2}$, Nemani Lalita ${ }^{3}$

${ }^{1}$ DM student, Department of Cardiology, NIMS, India

${ }^{2}$ Associate Professor, , Department of Neurology, NIMS

${ }^{3}$ Associate Professor, , Department of Cardiology, NIMS

Corresponding Author: Nemani Lalita

Email: drlalita775@gmail.com lakhs/mm3, blood urea was $19 \mathrm{mg} / \mathrm{dl}$, serum creatinine was $1 \mathrm{mg} / \mathrm{dl}$, Na+ was $136 \mathrm{mmoles} / \mathrm{L}, \mathrm{K}+$ was 5.2 mmoles/L , ESR was $5 \mathrm{~mm}$. ECG was within normal limits, 2D echocardiography showed no regional wall motion abnormality and good biventricular function. Neck vessel Doppler and MR Angiography of intracranial vessels showed right internal carotid artery(ICA) stenosis. Conventional carotid and coronary angiogram were done. Four vessel angiogram showed eccentric $80 \%$ stenosis of right ICA stenosis (Fig 1). Coronary angiogram showed $80 \%$ stenosis in distal LMCA and $70 \%$ stenosis in proximal LAD (Fig 2), stents were patent in RCA and PDA.

Figure 1: Carotid angiogram showing eccentric $80 \%$ stenosis of Rt ICA.

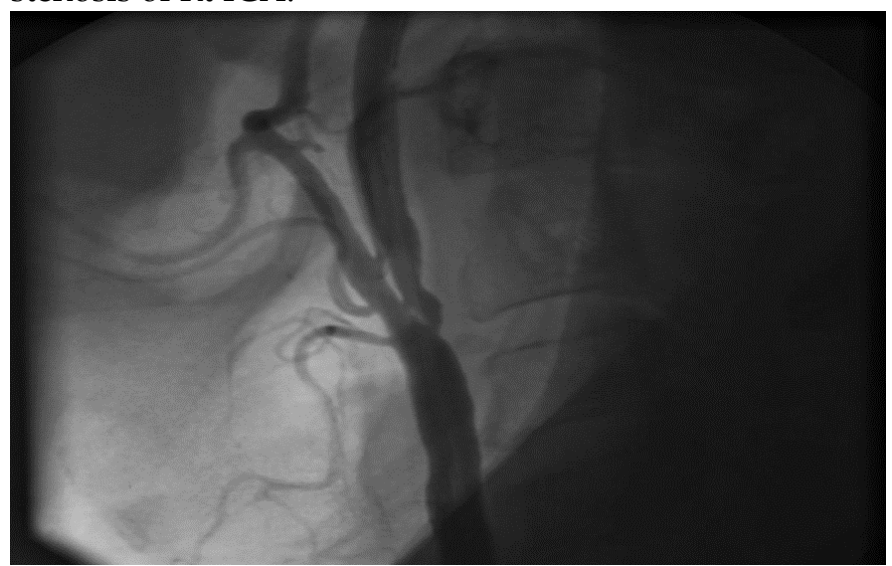

Figure 2: Coronary angiogram showing $80 \%$ stenosis in distal LMCA \& $70 \%$ stenosis in proximal LAD

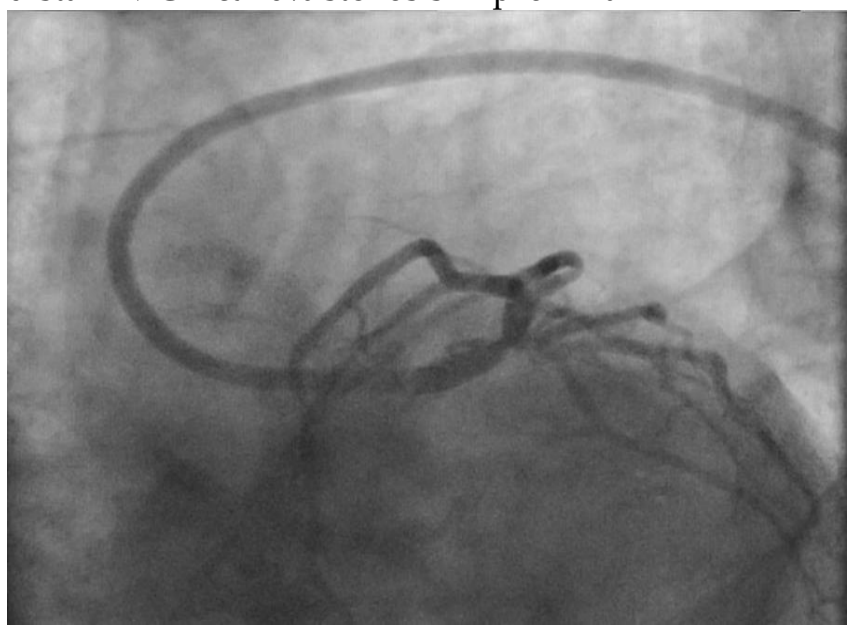




\section{DEBATE:}

\section{CAROTID ANGIOPLASTY FIRST}

The benefits of carotid intervention in symptomatic carotid disease are well documented and accepted [2,3]. The use of carotid angioplasty or stenting as an alternative to carotid end-arterectomy before cardiac revascularisation has been proposed as a less risky carotid revascularization strategy. The literature on carotid stenting contains numerous case series in which stenting is being performed as an alternative to carotid end-arterectomy in "high-risk" patients outside of randomized trials. The SAPPHIRE trial of stenting in high-risk patients included $80 \%$ of its patients from those with ischemic heart disease [4]. The main goal of performing carotid revascularization before coronary revascularisation is stroke prevention or at least reduction of the stroke rate, as stroke remains the major non-cardiac complication of coronary revascularisation [5]. After successful carotid revascularization the incidence of any stroke after coronary revascularisation decreases to $2.2 \%$ [6], which is the usual stroke risk associated with coronary revascularisation without coexistent carotid disease. In the SHARP study [7], in 4 high-volume canters, 101 consecutive patients with severe coronary and carotid disease underwent simultaneous carotid artery stenting and CABG. The 30day cumulative incidence of stroke, MI or death was $4 \%$ : 2 patients $(2 \%)$ had stroke immediately after carotid artery stenting before CABG, and another 2 patients died $(2 \%)$ in the post-operative period. Several observational studies have consistently reported that the risk of stroke associated with CABG is $<2 \%$ in patients with no significant carotid disease and $3 \%$ in patients with asymptomatic severe carotid stenosis. These figures, however, increase to $5 \%$ in those with bilateral carotid stenosis and to $7 \%$ to $11 \%$ in patients with carotid occlusion, therefore, stroke remains the major non-cardiac complication after CABG [8].

In the present case, patient presented with TIAs and asymptomatic about the CAD. But the limitation of the CAD status assessment is not accurate in this patient as he leads sedentary life. Despite this limitation symptomatic carotid disease with $>50 \%$ stenosis requires carotid revascularization first. As the anatomy of the aortic arch is suitable for percutaneous carotid intervention, along with previous history of radiation to the neck and chest, percutaneous carotid intervention preferred over carotid end-arterectomy for this patient.

\section{CORONARY ANGIOPLASTY FIRST}

If coronary revascularisation is not tackled first, then complications like bradycardia and hypotension which might arise during carotid intervention may be poorly tolerated in LMCA patient. Even though the hypotension during carotid angioplasty is transient, even single episode of hypotension precipitates angina in LMCA CAD and further hypotension perpetuates subsequently. So, we have to take every precaution to prevent the development of hypotension and bradycardia during carotid angioplasty.

Second, if coronary revascularisation is done without dealing with carotid artery disease patient will be at increased risk of stroke. Only after carotid intervention, PCI risk of CVA equalizes to routine risk for CVA of PCI.

Third, previous studies were on carotid angioplasty vs CABG, but not with PCI of LMCA. Risk of CVA in CABG is greater than PCI $[9,10]$. Now a days the scenario is different with simplified and safety of LMCA angioplasty, coronary angioplasty may be considered before carotid angioplasty.

\section{FOLLOW UP OF THE PATIENT:}

Decision to do both carotid and coronary revascularization was made. Right internal carotid artery stenting (Fig.3) was done followed one week later by stenting to LMCA to LAD (Fig.5) as the patient was not willing for coronary artery bypass grafting (even SYNTAX score was 18).

Figure 3: Carotid angiogram after Rt ICA angioplasty with stent.

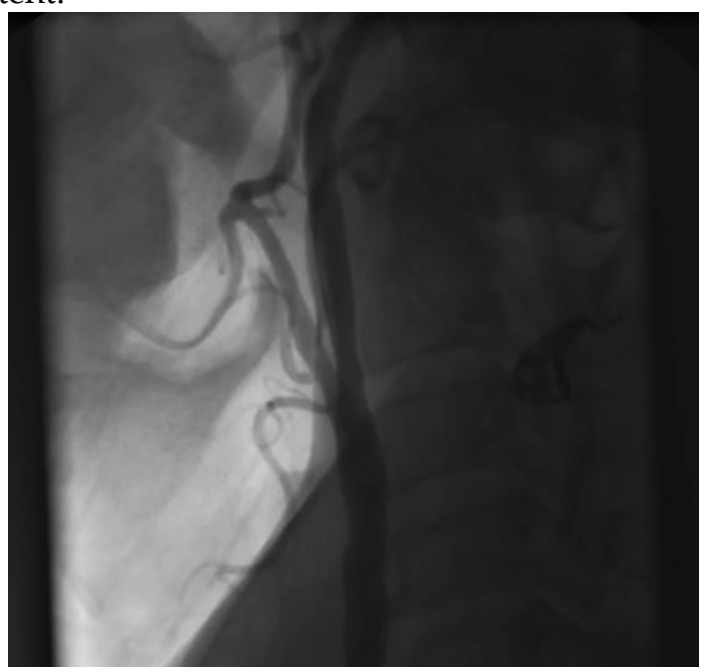


Figure 4: Coronary angiogram after LMCA to LAD stenting.

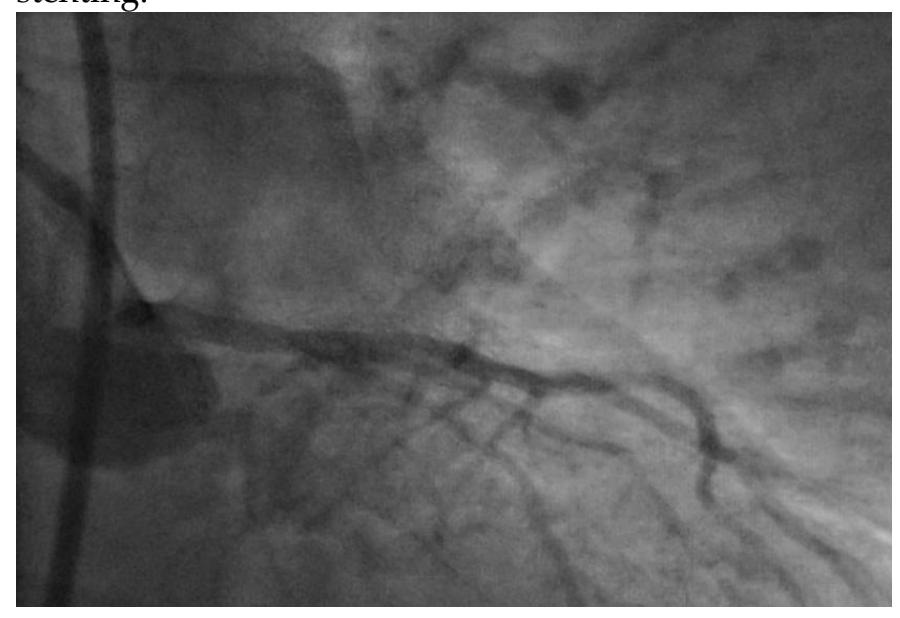

\section{CONCLUSION:}

A single ideal revascularization strategy for patients with coexisting severe carotid and coronary artery disease is unlikely to exist, and an individualized approach is mandatory, but this is ill-defined.

\section{REFERENCES:}

1. LaMuraglia GM, Brewster DC, Moncure AC, et al. Carotid endarter- ectomy at the millenium: what interventional therapy must match. Ann Surg2004;240:535-44.

2. Beneficial effect of carotid endarterectomy in symptomatic patients with high-grade carotid stenosis. North American Symptomatic Carotid Endarterectomy Trial Collaborators. N Engl J Med. 1991;325:445-453.

3. Rothwell PM, Eliasziw M, Gutnikov SA, Fox AJ, Taylor DW, Mayberg MR, Warlow CP, Barnett HJM. Analysis of pooled data from the randomised controlled trials of endarterectomy for symptomatic carotid stenosis. Lancet. 2003;361:107-116.

4. Yadav JS, Wholey MH, Kuntz RE, Fayad P, Katzen BT, Mishkel GJ, Bajwa TK, Whitlow P, Strickman NE, Jaff MR, Popma JJ, Snead DB, Cutlip DE, Firth BG, Ouriel K; Stenting and Angioplasty with Protection in Patients at High Risk for Endarterectomy Investigators. Protected carotid- artery stenting versus endarterectomy in high-risk patients. N Engl J Med. 2004;351:1493-1501.

5. Van der Heyden J, Suttorp MJ, Schepens MA: Revascularization strategy in patients with severe concurrent carotid and coronary artery disease: "Failure to move forward is reason to regress". J Cardiovasc Surg, 2009: 50; 55-62.

6. Guzman LA, Costa MA, Angiolillo DJ et al: A systematic review of outcomes in patients with staged carotid artery stenting and coronary artery bypass graft surgery. Stroke, 2008; 39(2): 361-65

7. Versaci F, Reimers B, Del Giudice C et al: Simultaneous hybrid revascularization by carotid stenting and coronary artery bypass grafting: the SHARP study. JACC Cardiovasc Interv, 2009; 2(5): 393-401

8. A.R. Naylor, R.L. Cuffe, P.M. Rothwell, P.R. Bell A systematic review of outcomes following staged and synchronous carotid endarterectomy and coronary artery bypass Eur J Vasc Endovasc Surg, 5 (2003), pp. 380-389.

9. Serruys PW, Unger F, Sousa JE, et al. Comparison of coronary-artery bypass surgery and stenting for the treatment of multivessel disease. $\mathrm{N}$ Engl J Med 2001;344:1117-24.

10. Tullio Palmerini, Giuseppe Biondi-Zoccai, et al. Risk of Stroke With Coronary Artery Bypass Graft Surgery Compared With Percutaneous Coronary Intervention. J Am Coll Cardiol. 2012;60(9):798-805. 